A new algorithm for the diagnosis of all forms of tuberculosis is required for South Africa

To the Editor: I write in response to 'Diagnosing Xpert MTB/RIFnegative TB: Impact and cost of alternative algorithms for South Africa' published in the SAMJ in February 2013.[1]

Modelling the impact and cost of alternative algorithms is essential to guide policy decisions; however, the entire National GeneXpert MTB/RIF (GXP) diagnostic algorithm requires major changes, rather than variations based on cost alone. ${ }^{[1]}$ This algorithm is suggested for all TB suspects and ignores the epidemiology of the South African (SA) tuberculosis (TB) epidemic, where $39 \%$ of cases notified have extrapulmonary TB (EPTB) or are unable to expectorate $(15 \%$ and $24 \%$, respectively). ${ }^{[2,3]}$

Given the high burden of TB disease in SA, an initial GXP on all patients with a positive symptom screen for TB is appropriate, despite the cost of the test. However, if the initial GXP is negative, particularly in HIV-positive individuals, a history and examination should direct further management to diagnose and treat the cause of the patient's symptoms. To continue blindly with the algorithm - especially the suggested $\mathrm{X} / \mathrm{X}$ alternative where any other possible form of $\mathrm{TB}$ or other opportunistic infection is ignored - is poor clinical medicine. ${ }^{[1]}$ Testing large numbers of patients with a second GXP for a $<3 \%$ positive rate is not economically prudent.

If the first GXP 'screen' in all symptomatic patients comes back negative, the algorithm should cover the non-TB pathology that may be causing the patient symptoms as well as the more common forms of EPTB. Examples of diagnostic pathways could be: (i) if the cough is prominent, presumptive antibiotics and second sputum for GXP; (ii) if dyspnoea or chest pain is predominant, a chest X-ray for pericardial and pleural effusion would be appropriate; (iii) significant lymphadenopathy on examination could proceed to a fine-needle aspirate (FNA) of a lymph node or empirical TB treatment with clinical follow-up where FNA is not available.

The diagnosis of TB in SA with our dual TB/HIV epidemic cannot rely on an algorithm that only considers pulmonary $\mathrm{TB}$; nor can the diagnostic search for TB exclude the individual patient, their 
symptoms and the very high possibility of diseases other than TB. An algorithm that uses sputum GXP as a screen in all TB suspects is appropriate in the SA context. However, if the first GXP is negative, a comprehensive healthcare system demands that further algorithms, that address the patient's major symptoms or signs, are developed.

\section{Andrew Black}

Wits Reproductive Health and HIV Institute, Hillbrow, Johannesburg, South Africa ablack@wrhi.ac.za

1. Schnippel K, Meyer-Rath G, Long L, Stevens WS, Sanne I, Rosen S. Diagnosing Xpert MTB/RIFnegative TB: Impact and cost of alternative algorithms for South Africa. S Afr Med J 2013;103(2):101106. [http://dx.doi.org/10.7196/SAMJ.6182]

2. Directorate Drug-Resistant TB, TB\&HIV. Management of Drug-Resistant Tuberculosis: Policy Guidelines. Pretoria: Government Press, 2011. http://www.doh.gov.za/docs/policy/2012/TBpolicy.pdf (accessed 15 March 2013).

3. World Health Organization. Global Tuberculosis Report 2012. Geneva: WHO, 2012. http://www.who. int/tb/publications/global_report/gtbr12_annex2.pdf (accessed 15 March 2013).

S Afr Med J 2013;103(6):355-356. DOI:10.7196/SAMJ.6896 